\title{
Percutaneous Radiofrequency Ablation of Spinal Osteoid Osteomas Using a Targeted Navigational Bipolar Electrode System
}

\author{
(D) A. Tomasian and (DJ.W. Jennings
}

\begin{abstract}
SUMMARY: Safe and effective percutaneous CT-guided radiofrequency ablation of spinal osteoid osteomas can be performed using a targeted navigational bipolar electrode system. Articulating bipolar electrodes with built-in thermocouples along an electrode shaft and variable generator wattage settings allow optimal nidus access, particularly in challenging locations; provide precise real-time monitoring of ablation zone volume and geometry; and minimize the risk of undesired thermal injury.
\end{abstract}

ABBREVIATION: RF = radiofrequency

D uring the past decade, investigators have successfully used percutaneous radiofrequency (RF) ablation for definitive treatment of spinal osteoid osteomas using traditional unipolar straight electrodes with variable ablation times ranging from 4 to 30 minutes after reaching a desired plateau temperature (typically $\left.90^{\circ} \mathrm{C}\right) .^{1-4}$

A recently introduced navigational bipolar RF ablation system has been successfully used for treatment of spinal metastases, ${ }^{5}$ which has several important advantages over traditional straight unipolar RF electrodes for the management of spinal lesions, particularly given the proximity of neural structures and the potential risk of undesired thermal injury. Most importantly, 2 built-in active thermocouples along the electrode shaft provide precise real-time monitoring of ablation zone volume and geometry and ensure that the entire nidus is safely ablated. Additionally, the articulating distal segment (tip) of the electrode can be curved in several directions, allowing optimal electrode positioning in different portions of the nidus from a single osseous entry site, particularly in larger lesions that would otherwise require more than one access points, and this feature is also advantageous for challenging-to-access lesions. Last, the bipolar electrode design eliminates the risk of thermal skin injury and obviates grounding pad placement.

Received June 15, 2018; accepted after revision July 24.

From the Department of Radiology (A.T.), University of Southern California, Los Angeles, California; and Mallinckrodt Institute of Radiology (J.W.J.), St. Louis, Missouri.

Please address correspondence to Anderanik Tomasian, MD, Department of Radiology, University of Southern California, 1500 San Pablo St, Los Angeles, CA 90033 e-mail: tomasian.andy@gmail.com

http://dx.doi.org/10.3174/ajnr.A5831

In this report, we describe the initial experience using a targeted multidirectional bipolar RF ablation electrode system for the treatment of spinal osteoid osteomas.

\section{MATERIALS AND METHODS}

Institutional review board approval was obtained to retrospectively review the institutional data base for patients who underwent RF ablation for the treatment of spinal osteoid osteomas between May 2015 and April 2018. Clinical manifestations included focal pain, particularly at night, which improved with nonsteroidal anti-inflammatory medications; painful scoliosis; and spinal stiffness. Imaging characteristics were best evaluated on CT and included an osteolytic nidus with surrounding osseous sclerosis. Informed consent was waived for retrospective participation. Recorded data included patient age, sex, treated anatomic site, and histologic diagnosis. Preprocedural imaging was reviewed to determine the nidus size and the shortest distance of the nidus from the central canal or neuroforamen. Procedural notes were reviewed to determine the total ablation time, generator wattage settings, use of electrode distal segment articulation, and the type of thermal protection. A procedure was considered technically successful if ablations encompassing the entire nidus volume were performed. Procedural complications were documented according to the Society of Interventional Radiology classification, ${ }^{6}$ based on patients' symptoms and physical examinations. Patients were clinically evaluated 2 hours after each procedure for potential acute complications such as hematoma formation or neurologic injury. Patients were discharged the day of procedure. Telephone follow-up was documented by a musculoskeletal nurse coordinator at 1- and 6-week postprocedure time points. Duration of clinical follow-up was recorded, and elec- 


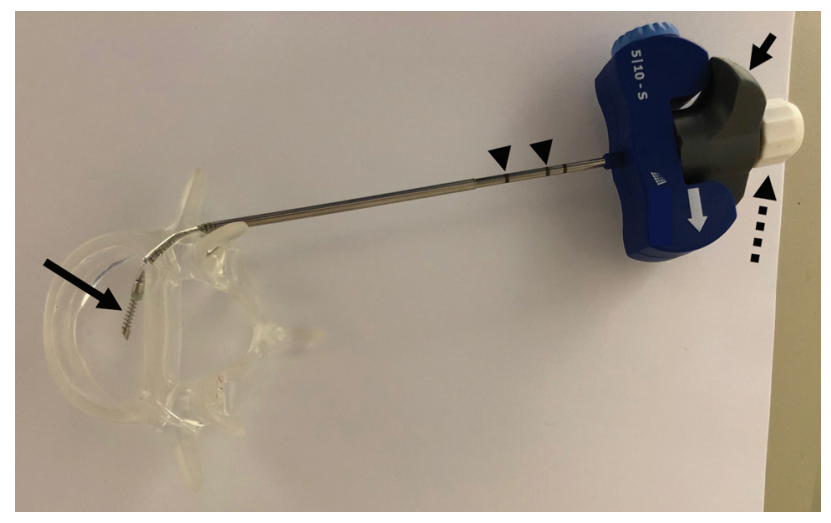

FIG 1. Navigational bipolar radiofrequency ablation electrode. The targeted multidirectional distal tip of the electrode (large arrow) can be articulated up to $90^{\circ}$ by turning the gray knob (small arrow) on the handle in the direction of the printed white arrow on the handle. Laser etchings (arrowheads) along the device shaft mark the exit point and deployment point of the electrode from the introducer cannula. After desired positioning within the nidus, the RF electrode tip is fully extended by turning the white knob (dotted arrow) at the handle. There are 2 active thermocouples embedded within the electrode located 5 and 10 $\mathrm{mm}$ from the center of ablation zone, which allow precise real-time monitoring of ablation zone volume and geometry.
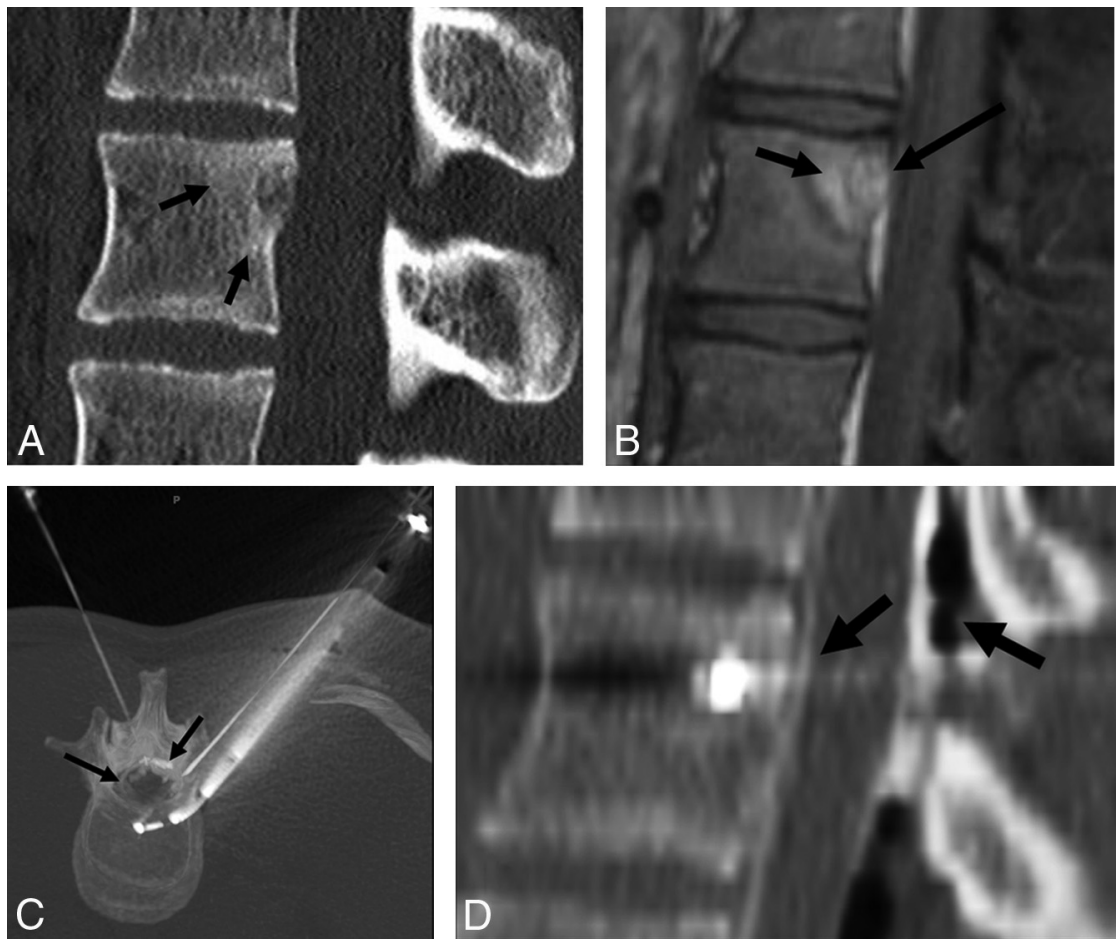

FIG 2. An 18-year-old woman with lumbar spine hypomobility and low back pain. This case highlights the advantages of articulating the distal electrode tip for challenging-to-access nidus location as well as real-time monitoring of ablation zone volume, considering the proximity to neural elements. Sagittal unenhanced CT $(A)$ and sagittal TT-weighted fat-saturated gadolinium-enhanced MR imaging $(B)$ show a partly mineralized nidus in the posterior L2 vertebral body abutting the posterior wall cortex and resulting in cortical thinning and slight convexity toward the central canal. Note surrounding reactive medullary sclerosis and reactive osteitis ( $A$ and $B$, small arrows) as well as partial obliteration of the anterior epidural space ( $B$, large arrow). Prone maximum-intensity-projection axial $C T(C)$ and sagittal $C T(D)$ during radiofrequency ablation show articulation of the distal tip of the navigational RF electrode placed via a lateral transpedicular approach for optimal access to the nidus in the central posterior vertebral body, which would be challenging to reach with traditional straight RF electrodes. Note the epidural injection of carbon dioxide and $5 \%$ dextrose in water (diluted in iodinated contrast) for active thermal protection ( $C$ and $D$, arrows). An 18-ga spinal needle is placed in the neuroforamen (C) for passive thermal protection (temperature monitoring). Somatosensory and motor-evoked potential monitoring was performed during the procedure. tronic medical records were reviewed for potential delayed com-

\section{Radiofrequency Ablation Equipment and Procedure}

The nidus was accessed using a 10-ga introducer needle. Nidus biopsy and channel creation for the electrode were then pered coaxially with a battery-powered hand drill and a 12-ga sisting of the Spine STAR Ablation device and the MetaSTAR rator. The ablation device is an articulating navigational biume are $15 \times 7 \times 7 \mathrm{~mm}$ when the thermocouple located $5 \mathrm{~mm}$ from center of the ablation zone (distal thermocouple) reaches $50^{\circ} \mathrm{C}$, and $20 \times 15 \times 15 \mathrm{~mm}$ when the thermocouple located 10 $\mathrm{mm}$ from center of ablation zone (proximal thermocouple) reaches $50^{\circ} \mathrm{C}$. As a safety feature, RF energy automatically stops when the proximal thermocouple registers $50^{\circ} \mathrm{C}$. There are laser etchings along the device that demarcate the exiting point of the electrode from the noninsulated working cannula to reduce the risk of ablating along the introducer tract (Fig 1). The MetaSTAR Generator provides 3-W, 5-W, 7.5-W, and 10-W power settings, which allow slow ablations. The generator also displays ablation time, impedance, and the 2 thermocouple temperature readings, which permit precise real-time monitoring of the ablation zone dimensions and geometry.

The navigational bipolar RF ablation electrode was subsequently positioned in the nidus center and articulated in different orientations, if needed, to ensure that the entire nidus was ablated (Figs 1 and 2).

Active and passive neural thermal protection techniques (Fig 2) were implemented and included an epidural or neuroforaminal injection of carbon dioxide and/or cooled 5\% dextrose in water, achieved by placement of an 18-ga spinal needle in the epidural space or in the neuroforamen and coaxial placement of a thermocouple to measure temperatures. ${ }^{7}$ Intraprocedural somatosensory and motor-evoked potential monitoring was performed when procedures were performed 


\begin{tabular}{|c|c|c|c|c|c|c|c|c|}
\hline $\begin{array}{l}\text { Patient } \\
\text { (No.) }\end{array}$ & $\begin{array}{c}\text { Age/Sex } \\
\text { (yr) }\end{array}$ & Anatomic Site & $\begin{array}{c}\text { Nidus } \\
\text { Size }(\mathrm{mm}) \\
\end{array}$ & $\begin{array}{c}\text { Distance }^{a} \\
(\mathrm{~mm})\end{array}$ & $\begin{array}{c}\text { Ablation } \\
\text { Time (min:sec) }\end{array}$ & Articulation & Wattage & $\begin{array}{c}\text { Follow-Up } \\
(\mathrm{mo})\end{array}$ \\
\hline $1^{b}$ & $32 / \mathrm{M}$ & C5 lateral mass & $8 \times 7 \times 5$ & 5 & $6: 09$ & Yes & 3 and 5 & 27 \\
\hline 2 & $16 / \mathrm{M}$ & C7 transverse process & $10 \times 8 \times 7$ & 1 & $5: 23$ & Yes & 3 and 5 & 26 \\
\hline 3 & $15 / F$ & L2 superior articular process & $10 \times 9 \times 9$ & 2 & 1:55 & Yes & 3 and 5 & 23 \\
\hline 4 & $6 / M$ & C7 superior articular process & $13 \times 9 \times 8$ & 0 & $5: 41$ & No & 3 and 5 & 19 \\
\hline 5 & $13 / \mathrm{M}$ & T10 pedicle & $19 \times 15 \times 13$ & 0 & $9: 04$ & No & 3 and 5 & 11 \\
\hline 6 & $18 / \mathrm{F}$ & L2 vertebral body & $7 \times 6 \times 6$ & 0 & $9: 08$ & Yes & 3 and 5 & 6 \\
\hline 7 & $13 / \mathrm{M}$ & C5 superior articular process & $10 \times 9 \times 7$ & 4 & $9: 57$ & No & 3 and 5 & 1 \\
\hline
\end{tabular}

a Shortest distance from the central canal/neuroforamen. A distance of $0 \mathrm{~mm}$ indicates that the nidus involved the cortex, compromising the central canal or neuroforamen.

'This patient's data have been previously published. ${ }^{8}$

with the patient under general anesthesia for early detection of potentially impending thermal nerve/spinal cord injury. ${ }^{7}$ Additionally, an immediate postablation prophylactic ipsilateral nerve root block was performed when the nidus abutted the neuroforamen with no intact cortex. This was achieved by neuroforaminal injection of 10 $\mathrm{mg}$ of dexamethasone to improve postablation inflammation.

\section{RESULTS}

Seven spinal osteoid osteomas were RF-ablated using the targeted multidirectional bipolar electrode system. All ablations were technically successful with no complications. All tumors were accessed via a single osseous channel. Biopsy was performed in 5 patients, and all were diagnostic of osteoid osteoma. No biopsy specimen was obtained in patient 3 , and the nidus was not accessible using a transpedicular approach with a straight biopsy needle in patient 6 due to the central location in the posterior vertebral body. All patients had complete pain resolution following the procedures. Patient 4 developed slight intermittent pain 4 months following the procedure, which remained unchanged at the 19-month follow-up. Details of the patient cohort are summarized in the Table.

\section{DISCUSSION}

This initial report demonstrates that unique features of the targeted navigational bipolar STAR Tumor Ablation System successfully used to treat spinal metastases and primarily appendicular osteoid osteo$\mathrm{mas}^{5,8-11}$ can also be used for safe and effective treatment of spinal osteoid osteomas. Radiofrequency ablation of spinal osteoid osteomas poses a unique challenge due to the proximity of neural structures, particularly considering the location of most lesions within the posterior spinal elements. Preserved spinal cortical bone, flow of CSF, and the epidural space have been described as protective factors against undesired RF energy propagation. ${ }^{12}$ Our experience highlights the importance of precise real-time monitoring of ablation zone volume and geometry made possible by 2 active embedded thermocouples along the electrode, a feature that is a recent development in RF ablation electrode design technology. This allows the operator to ensure that sufficiently high temperature is generated over a volume that encompasses the entire nidus while minimizing the risk of undesired thermal injury, and it is vital when ablating close to the spinal cord or nerve roots.

CSF and vessels may result in convective cooling (heat-sink effect) that hinders RF energy deposition within the nidus. In our experience, variable power settings provided by the MetaSTAR Generator permit slow ramping of temperatures. We believe this results in reduction of heat sink and improvement of efficacy while minimizing undesired heat dispersion and impedance is- sues, particularly in densely mineralized lesions. The 3 cases in this series in which the osteoid osteoma nidus was $<1 \mathrm{~mm}$ from the closest neural element or with no intact interposing cortex demonstrate that these lesions can be safely ablated with appropriate neural protection and careful monitoring of ablation zone dimensions (Fig 2). We recommend that both passive and active neural thermal protective measures be implemented for radiofrequency ablation of spinal osteoid osteomas, particularly with lesions closer than $5 \mathrm{~mm}$ to the spinal cord or nerve roots.

Because the entire nidus must be ablated to ensure a definitive cure and a nidus of $>12 \mathrm{~mm}$ has been described as an independent risk factor for recurrence, a larger nidus may require placement of more than one straight RF electrode to achieve sufficient overlapping ablation volume through separate osseous access sites, further compromising bone integrity and predisposing to potential fracture. The articulating distal segment of the navigational system affords electrode placement within any desired location within the nidus from a single bone-entry site, a characteristic that is particularly useful in larger lesions. This feature also facilitates access to difficult-to-reach nidus locations, particularly in the cervical spine and adjacent to the vertebral body posterior wall (Fig 2), where they would otherwise be challenging to access using traditional straight RF electrodes.

In addition, the risk of skin thermal injury inherent in unipolar electrodes due to inadequate dispersion of RF energy on the skin surface at the region of grounding pads is eliminated using a bipolar RF electrode design.

\section{CONCLUSIONS}

Safe and effective CT-guided radiofrequency ablation of spinal osteoid osteomas can be achieved using a targeted navigational bipolar electrode system.

Disclosures: Jack W. Jennings—RELATED: Consulting Fee or Honorarium: Merit Medical Systems, Comments: ablation training courses and consultation; UNRELATED: Consultancy: Bard Peripheral Vascular; Expert Testimony: Bard Peripheral Vascular.

\section{REFERENCES}

1. Rybak LD, Gangi A, Buy X, et al. Thermal ablation of spinal osteoid osteomas close to neural elements: technical considerations. AJR Am J Roentgenol 2010;195:W293-98 CrossRef Medline

2. Vidoni A, Grainger M, James S. Experience of neuroprotective air injection during radiofrequency ablation (RFA) of spinal osteoid osteoma. Eur Radiol 2018;28:4146-50 CrossRef Medline

3. Vanderschueren GM, Obermann WR, Dijkstra SP, et al. Radiofrequency ablation of spinal osteoid osteoma: clinical outcome. Spine (Phila Pa 1976) 2009;34:901-04 CrossRef Medline

4. Albisinni U, Facchini G, Spinnato P, et al. Spinal osteoid osteoma:

AJNR Am J Neuroradiol 39:2385-88 Dec 2018 www.ajnr.org 
efficacy and safety of radiofrequency ablation. Skeletal Radiol 2017; 46:1087-94 CrossRef Medline

5. Hillen TJ, Anchala P, Friedman MV, et al. Treatment of metastatic posterior vertebral body osseous tumors by using a targeted bipolar radiofrequency ablation device: technical note. Radiology 2014;273: 261-67 CrossRef Medline

6. Ahmed M, Solbiati L, Brace CL, et al; International Working Group on Image-Guided Tumor Ablation; Interventional Oncology Sans Frontières Expert Panel; Technology Assessment Committee of the Society of Interventional Radiology; Standard of Practice Committee of the Cardiovascular and Interventional Radiological Society of Europe. Image-guided tumor ablation: standardization of terminology and reporting criteria—a 10-year update. J Vasc Interv Radiol 2014;25:1691-705.e4 CrossRef Medline

7. Tomasian A, Gangi A, Wallace AN, et al. Percutaneous thermal ablation of spinal metastases: recent advances and review. $A J R A m J$ Roentgenol 2018;210:142-52 CrossRef Medline
8. Wallace AN, Tomasian A, Chang RO, et al. Treatment of osteoid osteomas using a navigational bipolar radiofrequency ablation system. Cardiovasc Intervent Radiol 2016;39:768-72 CrossRef Medline

9. Wallace AN, Tomasian A, Vaswani D, et al. Radiographic local control of spinal metastases with percutaneous radiofrequency ablation and vertebral augmentation. AJNR Am J Neuroradiol 2016;37: 759-65 CrossRef Medline

10. Greenwood TJ, Wallace A, Friedman MV, et al. Combined ablation and radiation therapy of spinal metastases: a novel multimodality treatment approach. Pain Physician 2015;18:573-81 Medline

11. Anchala PR, Irving WD, Hillen TJ, et al. Treatment of metastatic spinal lesions with a navigational bipolar radiofrequency ablation device: a multicenter retrospective study. Pain Physician 2014;17: 317-27 Medline

12. Dupuy DE, Hong R, Oliver B, et al. Radiofrequency ablation of spinal tumors: temperature distribution in the spinal canal. $A J R A m J$ Roentgenol 2000;175:1263-66 CrossRef Medline 